\title{
Hydrogen diffusion in creep-resistant 9\% Cr P91 multi-layer weld metal
}

\author{
Michael Rhode ${ }^{1,2}$ (I) $\cdot$ Tim Richter $^{1} \cdot$ Peter Mayr $^{3,4} \cdot$ Alexander Nitsche $^{4} \cdot$ Tobias Mente $^{1} \cdot$ Thomas Böllinghaus $^{1}$
}

Received: 19 August 2019 / Accepted: 11 November 2019/Published online: 6 December 2019

(C) International Institute of Welding 2019

\begin{abstract}
Welded components of P91 9\% Cr steel demand for careful welding fabrication with necessary post weld heat treatment (PWHT). Before the PWHT, a hydrogen removal heat treatment is necessary for avoidance of hydrogen assisted cracking (HAC). In this context, the microstructure and temperature-dependent hydrogen diffusion is important, and reliable diffusion coefficients of $\mathrm{P} 91$ weld metal are rare. For that reason, the diffusion behavior of $\mathrm{P} 91$ multi-layer weld metal was investigated for as-welded (AW) and PWHT condition by electrochemical permeation experiments at room temperature and carrier gas hot extraction (CGHE) from 100 to $400{ }^{\circ} \mathrm{C}$. Hydrogen diffusion coefficients were calculated, and the corresponding hydrogen concentration was measured. It was ascertained that both heat treatment conditions show significant differences. At room temperature the AW condition showed significant hydrogen trapping expressed by to seven times lower diffusion coefficients. A preferred diffusion direction was found in perpendicular direction expressed by high permeability. The CGHE experiments revealed lower diffusion coefficients for the AW condition up to $400{ }^{\circ} \mathrm{C}$. In this context, a hydrogen concentration of approximately $21 \mathrm{ml} / 100 \mathrm{~g}$ was still trapped at $100^{\circ} \mathrm{C}$. For that reason, a certain HAC susceptibility of as-welded P91 weld metal cannot be excluded, and hydrogen removal should be done before PWHT.
\end{abstract}

Keywords Creep resisting materials $\cdot$ Diffusion $\cdot$ Hydrogen embrittlement $\cdot$ Weld metal $\cdot$ PWHT $\cdot$ Microstructure

\section{Introduction}

Creep-resistant 9\% Cr steels like T/P91 (X10CrMoVNb9-1) are widely used for conventional power generation in fossil

Recommended for publication by Commission IX - Behaviour of Metals Subjected to Welding

Michael Rhode

michael.rhode@bam.de

1 Department 9 - Component Safety, Bundesanstalt für Materialforschung und-prüfung (BAM), Unter den Eichen 87, 12205 Berlin, Germany

2 Institute for Materials Science and Joining Technology, Otto-von-Guericke-University Magdeburg, Universitätsplatz 2, 39106 Magdeburg, Germany

3 Department of Mechanical Engineering, Chair of Materials Engineering of Additive Manufacturing, Technical University of Munich, Boltzmannstr. 15, 85748 Garching, Germany

4 Institute for Joining and Assembly, Chair of Welding Engineering, Technical University of Chemnitz, Reichenhainer Strasse 70, 09126 Chemnitz, Germany and nuclear power plants [1-3] and as structural materials for latent heat storage systems [4], but are also candidate materials for fusion reactor applications [5]. For component fabrication, fusion welding is typically carried out. In this context, the martensitic microstructure demands a careful welding fabrication $[2,3]$. The welding process of martensitic $\mathrm{Cr}$ steels is followed by a multi-step procedure. So-called hydrogen removal heat treatment (HRHT) or dehydrogenation heat treatment (DHT) is carried out first and is essential to avoid hydrogen assisted cracking, especially delayed cracking. It is followed by cooling the weld joint to room temperature to ensure martensitic transformation. Finally, the welded component is subjected to the post weld heat treatment (PWHT), which is done at temperatures above $650{ }^{\circ} \mathrm{C}$ (for reduction of residual stresses, decrease of hardness, and improvement of mechanical properties).

If the HRHT/DHT (or so-called soaking) is not applied, wrong temperature or insufficient dwell time is used, hydrogen assisted cracking (HAC) of welded Cr-Mo steel joints can appear directly after welding or during later application of the component [6-9]. In general, HAC is a result of the interaction of a crack-critical hydrogen concentration dissolved in a 
mechanically loaded and crack-susceptible microstructure [10] [11]. In this context, 9\% Cr steels are generally susceptible to HAC due to considerable amounts of martensite. The hydrogen effect manifests in a significant degradation effect on the ductility [7, 9, 12-14]. Hydrogen sources are typically the weld consumable. For that reason, weld consumables should already only contain reduced hydrogen levels. In addition, surface contaminants like oil or grease are considerable hydrogen sources, and a clean workpiece surface before welding is necessary [15] [16],.

\section{Background on diffusion in creep-resistant 9\% Cr steels}

Various temperature-dependent diffusion coefficients are available in literature. These can be used to give recommendations on HRHT temperature or holding time like in [17-20] and are especially useful in numerical calculations. In this context, the necessary holding time for a given plate thickness decreases with increasing temperature. The reason is the general temperature dependency of the diffusion in solid-state bodies, which can be expressed by Eq. 1. In this context, the exponential factor is the so-called Boltzmann factor.

$$
\mathbf{D}=\mathbf{D}_{0} * \mathbf{e}^{-\frac{E_{\mathrm{A}}}{\mathrm{R}^{*} \mathrm{~T}}}
$$

where $D$ is the diffusion coefficient and $D_{0}$ is a materialspecific constant, $E_{\mathrm{A}}$ is the so-called activation energy for diffusion (in $\mathrm{kJ} / \mathrm{mol}$ ), $R$ is the universal gas constant (8.31 $\mathrm{J} / \mathrm{mol}^{*} \mathrm{~K}$ ), and $T$ is the absolute temperature in $\mathrm{K}$.

HRHT- procedures must be economically efficient. This means that temperature and holding time should only as high as necessary. To estimate these necessary parameters, hydrogen diffusion coefficients are necessary for different temperature levels. In that connection, it is difficult to identify "reliable" diffusion coefficients from literature. For example, Boellinghaus et al. [21] reported a range of three orders of magnitude for ferritic and martensitic steels already at room temperature. This behavior can be adopted for Cr-Mo creepresistant steels as well. A big variety of hydrogen diffusion coefficients can be found in the literature for low alloyed CrMo and Cr-Mo-V steels [9, 12, 22-29]. In contrast, the number of diffusion coefficients for martensitic $9 \% \mathrm{Cr}$ steels is limited [9, 30-32]. Figure 1 shows a selection of diffusion coefficients for low-alloyed bainitic Cr-Mo steels (black and gray data) and for high-alloyed martensitic creep-resistant steels like P91 or P92 (red data). The dashed lines are included to emphasize the high temperature diffusion data.

In general, the diffusion coefficients of the low-alloyed CrMo are higher than the high-alloyed 9\% Cr steels. This behavior is influenced by the heat treatment condition and partially

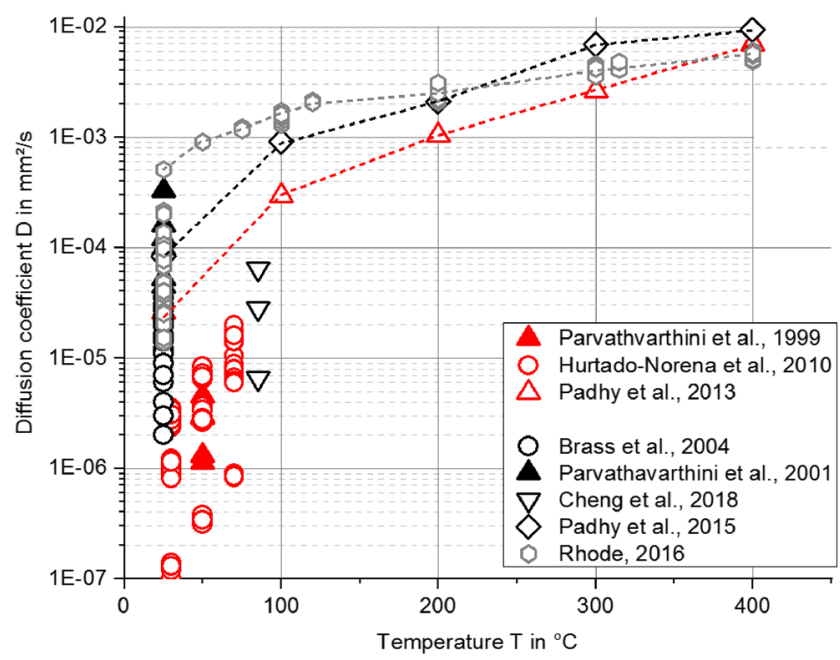

Fig. 1 Hydrogen diffusion coefficients in low- and high-alloyed $\mathrm{Cr}-\mathrm{Mo}$ creep-resistant steels [12, 23-26, 31, 32]

due to the microstructure. Nonetheless, the chemical composition of the steel grades has a significant influence in terms of low-alloyed or high-alloyed. In addition, contrary diffusion coefficients can occur. For example, the coefficients of Cheng et al. [25] are lower at $80{ }^{\circ} \mathrm{C}$ than the values reported in $[12,24]$ at $25^{\circ} \mathrm{C}$. In accordance to Eq. 1, this behavior is somewhat confusing. This shows the necessity of the determination of reliable diffusion coefficients. In accordance to [31], hydrogen diffusion coefficients varied by factor ten for a $9 \mathrm{Cr}-$ 1 Mo steel in different quenched and annealed condition. But despite the undoubtable microstructure effect, experimental boundary conditions like the sample thickness can influence the calculation of the effective diffusion coefficient [33] [34].

The importance of reliable diffusion coefficients is demonstrated by the averaged diffusion depth, i.e., the thickness of a layer that hydrogen can penetrate within a given time. In terms of welding, it allows an approximation which HRHT time is necessary to decrease the hydrogen concentration [15]. This HRHT time is connected to the diffusion coefficient at a given HRHT temperature. There are different solutions and approximations for diffusion problems, for example given in [35, 36]. In accordance to [35], it can be expressed by Eq. 2.

$\bar{X}=\sqrt{4 \times \mathrm{D} \times \mathrm{t}}$

where $\overline{\mathrm{X}}$ represents the averaged diffusion depth (or plate thickness), $D$ is the temperature-dependent diffusion coefficient (see Eq. 1), and $t$ is the dwell time. If $\overline{\mathrm{X}}$ is constant, two different diffusion coefficients $D_{1}$ and $D_{2}$ for a constant temperature lead after some simple mathematical transformations to Eq. 3, which is a equivalence condition between certain diffusion coeffcient and time.

$\mathrm{D}_{1} * \mathrm{t}_{1}=\mathrm{D}_{2} * \mathrm{t}_{2}$ 
Table 1 Measured chemical composition of P91 WM compared with nominal composition in accordance to (values in wt.- $\%, \mathrm{Fe}$ - balance)

\begin{tabular}{ccccc}
\hline Element & $\mathbf{C}$ & $\mathbf{C r}$ & $\mathbf{M o}$ & $\mathbf{V}$ \\
GD-OES & 0.09 & 9.50 & 0.96 & 0.20 \\
[37] & 0.08 to 0.13 & 8.00 to 10.50 & 0.85 to 1.20 & 0.15 to 0.30 \\
Element & $\mathbf{N b}$ & $\mathbf{S i}$ & $\mathbf{M n}$ & $\mathbf{P}+\mathbf{S}$ \\
GD-OES & 0.026 & 0.21 & 0.80 & 0.02 \\
{$[37]$} & Max. 0.100 & Max. 0.50 & Max. 1.20 & Max. 0.03 \\
\hline
\end{tabular}

Equation 3 shows the necessary diffusion coefficient and time equivalence under the boundary condition of constant temperature and plate thickness. If $D_{1}$ is one magnitude higher $(10 \times)$ than $D_{2}, t_{1}$ must be 10 -times lower than $t_{2}$. Hence, an increased diffusion coefficient would lead to shorter diffusion time. Theoretical calculations showed that for the entire hydrogen removal, a dwell time of 5 to $12 \mathrm{~h}$ is necessary for a given plate thickness of $10 \mathrm{~mm}$ [15]. The different time is the result of the applied lowest or highest diffusion coefficient at $200{ }^{\circ} \mathrm{C}$. This must necessarily lead to inconsistencies. With respect to real applications, this demonstrates the economic impact of unnecessarily prolonged HRHT time. It must be considered that the temperature is the driving force for diffusion. Hence, reliable temperaturedependent diffusion coefficients are essential for realistic HRHT procedures.

For that reason, the focus of this study was to investigate the influence of microstructure and heat treatment condition on hydrogen diffusion in $9 \% \mathrm{Cr}$ steel weld joints. For this purpose, a P91 multi-layer weld metal was investigated. Two different techniques (permeation and carrier gas hot extraction) were used to characterize both the diffusion behavior and the hydrogen solubility.

\section{Materials and methods}

\subsection{Weld metal production and sample machining}

The chemical composition of the P91 weld metal (WM) was measured by glow discharge optical emission spectroscopy (GD-OES). The measured values are given in Table 1 and is compared with the nominal chemical composition in accordance to EN ISO 17634 [37].

The P91 weld metal specimens were extracted from a weld metal bloc that was produced by manual multi-layer welding on a S355 steel plate as shown in Fig. 2. The welding process was gas metal arc welding (GMAW). A rutile-basic flux cored wire electrode (Böhler C 9 MV Ti-FD type, specified in [38]) was used with $82 \%$ Ar-based and $18 \% \mathrm{CO}_{2}$-containing shielding gas.

The preheat temperature was $200{ }^{\circ} \mathrm{C}$ and interpass temperature was $280^{\circ} \mathrm{C}$. The applied welding parameters are the following: wire feed speed $13 \mathrm{~m} / \mathrm{min}$, welding current 250 to $270 \mathrm{~A}$, arc voltage 25 to $27 \mathrm{~V}$, welding speed approximately 30 to $40 \mathrm{~cm} /$ $\mathrm{min}$. The multi-layer welding was applied to manufacture pure weld metal bloc with approximately 40-mm thickness, $60-\mathrm{mm}$ width, and 160-mm length. After welding, this bloc was cut into two pieces with approximately $80-\mathrm{mm}$ length. One part was in "as-welded" (AW) condition, and the second part was subjected further to post weld heat treatment (PWHT) at $760{ }^{\circ} \mathrm{C}$ for $4 \mathrm{~h}$. The aim was to produce weld metal samples in two different heat treatment conditions for the hydrogen diffusion experiments:

- The first condition was the as-welded multi-layer weld metal. As shown in Fig. 3a, the AW condition is represented by a martensitic microstructure (indicated by the needle shapelike laths). The microhardness was relatively high at 404 HV0.5 \pm 27 . Some $\delta$-ferrite has been identified by using Lichtenegger and Bloch (LBIII) etchant. The ferrite amounts did not affect the microhardness. Although, no further SEM/ TEM analysis was conducted, generally in P91 WM small-
Fig. 2 Weld metal bloc. (a) Real bloc. (b) Schematic with indication of (permeation) specimen direction

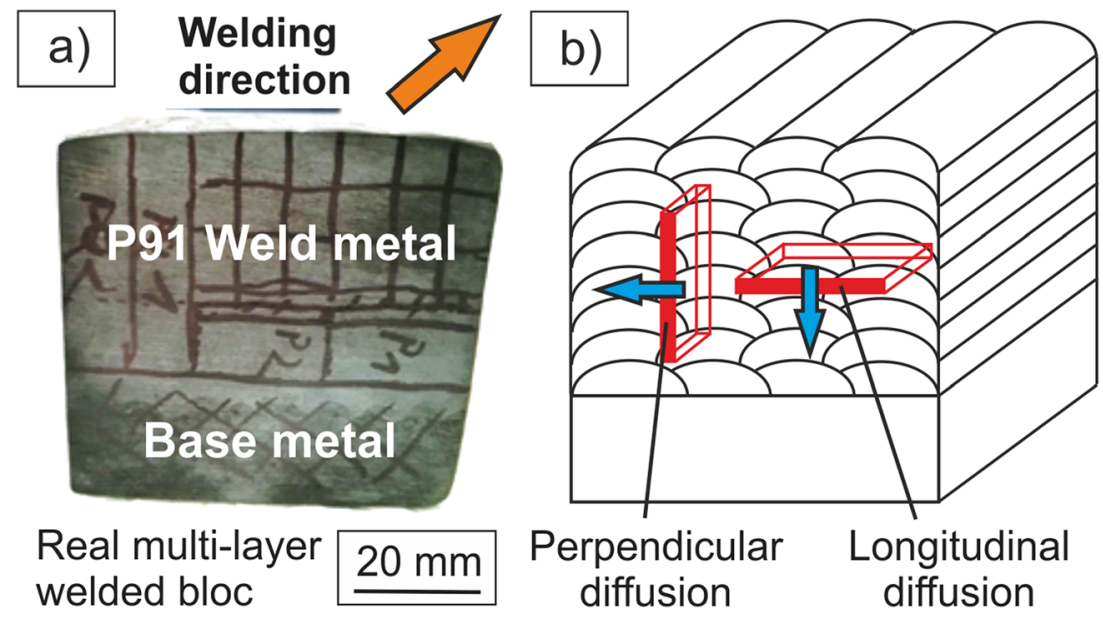



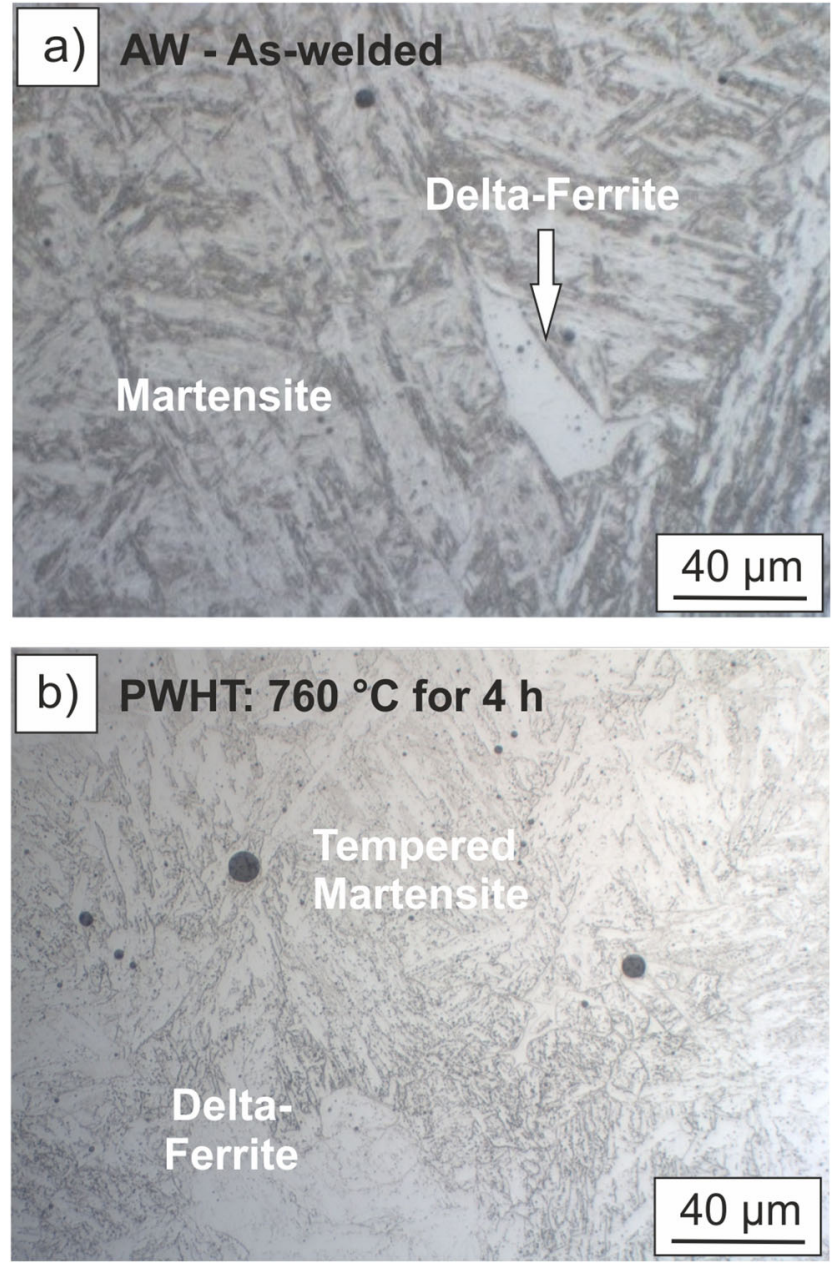

Fig. 3 Weld metal microstructure. (a) AW. (b) PWHT $760{ }^{\circ} \mathrm{C}$ for $4 \mathrm{~h}$

sized MX particles ( $\mathrm{M}=\mathrm{V}, \mathrm{Nb}$ and for example $\mathrm{X}=\mathrm{C})$ or $\mathrm{M}_{23} \mathrm{C}_{6}$ carbides ( $\mathrm{M}=\mathrm{Cr}$, Mo) can be typically found within the grains, at grain boundaries and between martensite laths [39].

- For the second condition, the weld metal was further subjected to a PWHT in accordance to welding recommendations given in As shown in Fig. 3b, the microstructure contained tempered martensite and amounts of ferrite (which was not eliminated by PWHT). The tempering influence was indicated by the significantly reduced microhardness ( $231 \mathrm{HV} 0.5 \pm 7$ ). In accordance to, it is assumed that the precipitated MX particles or $\mathrm{M}_{23} \mathrm{C}_{6}$ carbides began to coarsen during PWHT.

Two different specimen types were machined for the different experiments:

- By wire erosion / EDM , thin membranes with $20 \mathrm{~mm}$ width, $25 \mathrm{~mm}$ length, and thickness of $0.5 \mathrm{~mm}$ for the permeation experiments. Before the experiments, the specimens had been ground with $\mathrm{SiC} 500$ grit paper. Additionally, two different microstructure directions were considered, i.e., within one layer and across different layers (see Fig. 2). The aim was to investigate a preferred diffusion direction, see section 3.2.

- By cutting and turning, cylindrical specimens for the carrier gas hot extraction (CGHE). They had a diameter of $3 \mathrm{~mm}$ and $20-\mathrm{mm}$ length Due to the limited amount of weld metal, they had only been extracted in welding direction and ground before electrochemical charging. For the charging procedure, see section 3.3. For the electrochemical charging, the samples had a circumferential notch (depth $0.25 \mathrm{~mm}$ ) at the end of one side to mount a Pt wire (necessary for electrical connection to the Galvanostat, see Fig. 4).

\subsection{Hydrogen diffusion at room temperature by permeation experiments}

\subsubsection{Permeation technique}

For the permeation experiments, an electrochemical double cell was used in accordance to [40] and described in ISO 17081 [41]. In general, the double cell consists of a cathodic (-) and anodic (+) compartment, which is separated by a thin metallic membrane. This membrane is made from the material of interest (in our case the P91 weld metal). The permeation experiment setup is schematically shown in Fig. 4a. Figure $4 \mathrm{~b}$ shows the respective experimental setup for hydrogen charging of the cylindrical samples (charging procedure details see section 3.3)

The hydrogen is generated at the cathodic (-) polarized side from an acidic electrolyte. For this purpose, $0.1 \mathrm{M} \mathrm{H}_{2} \mathrm{SO}_{4}$ in combination with $0.05 \mathrm{M} \mathrm{NaAsO}_{2}$ acted as recombination poison. The galvanostatic charging current was set to $0.60 \mathrm{~mA} / \mathrm{cm}^{2}$. After absorption into the material, hydrogen diffuses through the specimen and desorbs at the anodic $(+200 \mathrm{mV}$ vs. $\mathrm{Ag} / \mathrm{AgCl}$ reference electrode) polarized exit side. In this case, $0.1 \mathrm{M} \mathrm{NaOH}$ is used. The desorbing hydrogen ions reduce the hydroxide ions $(\mathrm{OH}-)$. This electron transfer corresponds to a current (I typically in $\mu \mathrm{A}$ ), which is measured. Via the active hydrogen charged area (approx. $200 \mathrm{~mm}^{2}$ ), the current is transformed into a current density "i" in $\mathrm{A} / \mathrm{mm}^{2}$. Using Faraday's law, it can be converted to a time-dependent hydrogen mass flux, in accordance to Eq. 4. In addition, the 
Fig. 4 Experimental setup for (a) PT-experiments with hydrogen charging and detection in accordance to and (b) hydrogen charging of cylindrical samples for CGHE experiments

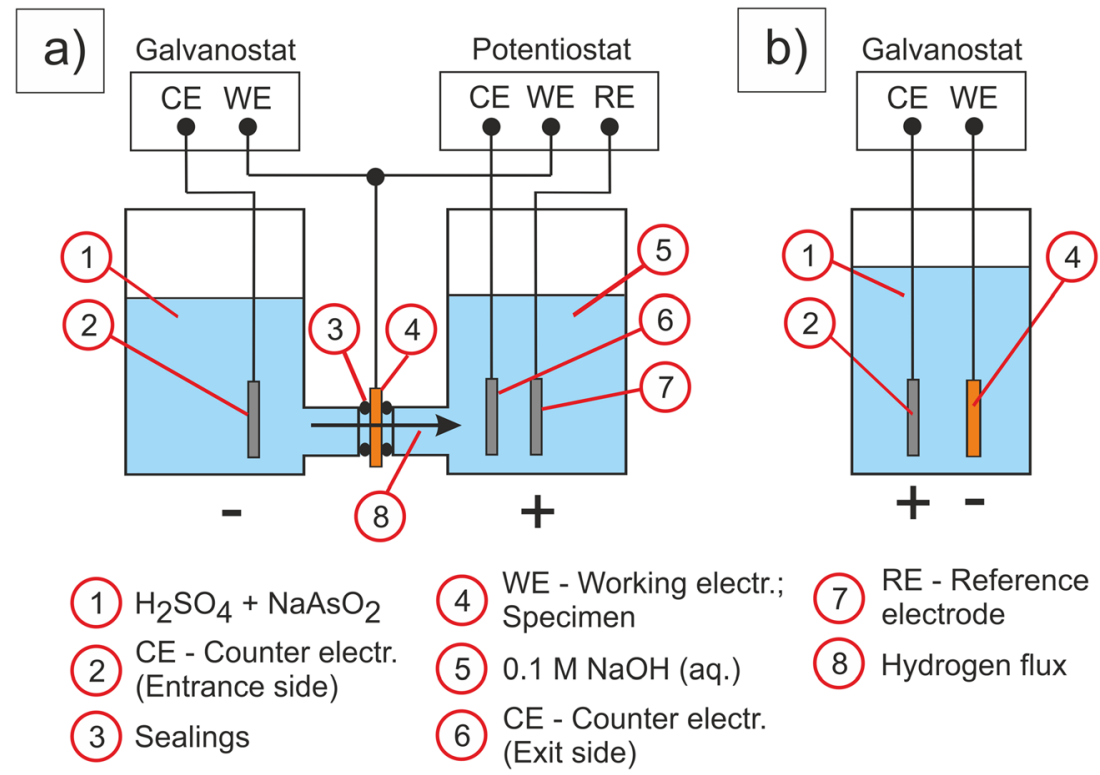

permeability " $\phi$ " (in $\mathrm{mol} / \mathrm{mm} \times \mathrm{s}$ ) is calculated in accordance to Eq. 5. It is defined as the maximum hydrogen flux " $\mathrm{J}_{\max }$ " (or expressed as " $\mathrm{i}_{\max }$ ", the corresponding maximum current density) across the specimen thickness "L" . "F" is Faraday constant 96,485 As/mol and " $\mathrm{z}$ " is the number of transferred electrons $(=1)$.

$J_{(t)}=\frac{i_{(t)}}{z \times F}$

$\phi=J_{\max } \times L$

The typical permeation transient is an S-shape curve (rising hydrogen flux). This curve reaches a steady state condition in finite time.

\subsubsection{Calculation of diffusion coefficients}

In our study, we used two different methods for calculation of hydrogen diffusion coefficients at room temperature, namely, the time-lag method (Fig. 5a) and the inflection point method (Fig. $5 b)$. In both schematics, " $t_{b}$ " represents the breakthrough-time, which encompasses the elapsed time until first hydrogen is detected.

The time-lag method (Fig. 5a) demands the so-called time $t_{\text {lag. }}$. It represents the elapsed time until $63 \%$ of maximum current density "imax" (corresponding hydrogen flux " $\mathrm{J}_{\max }$ ") is reached . The time-lag diffusion coefficient " $\mathrm{D}_{\text {lag }}$ " is calculated in accordance to Eq. 6.

The inflection point method (Fig. 5b) demands the calculation of the slope at the inflection point of the permeation transient. In accordance to Eq. 7, this point is reached at $24.42 \%$ of " $\mathrm{i}_{\max }$ " or " $\mathrm{J}_{\max }$ " respectively [41]. The inflection
Fig. 5 Time-dependent hydrogen mass flux. Determination of (a) lag-time and (b) slope at inflection point, in accordance to [12, 40-42]
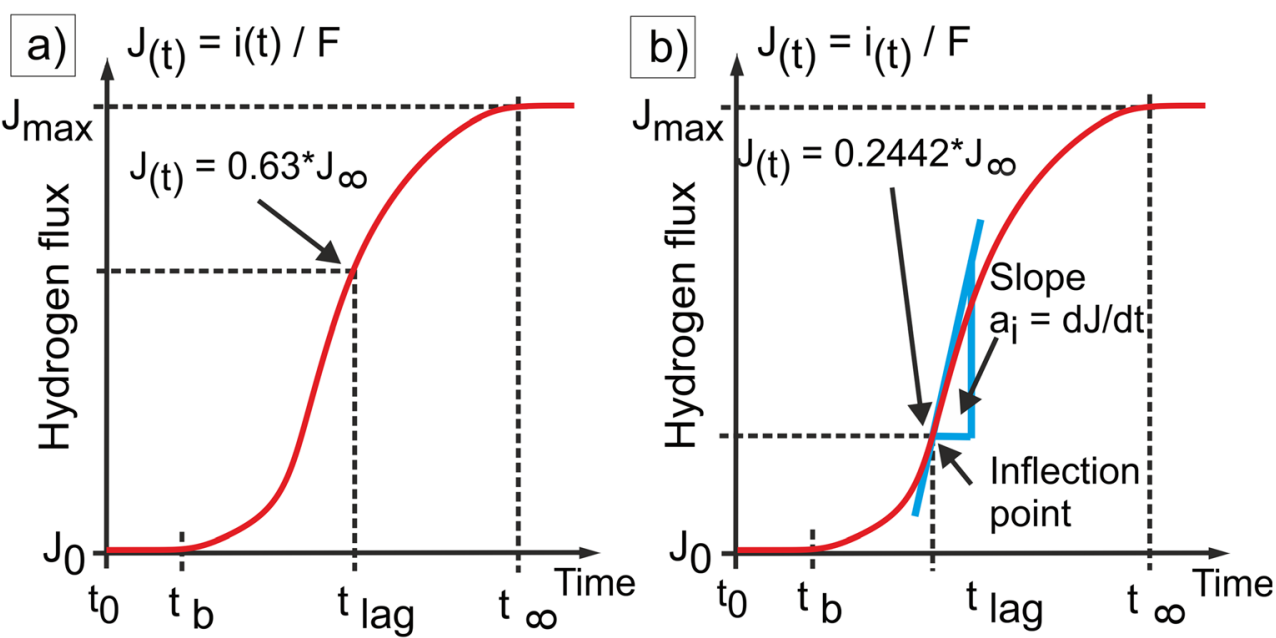
point diffusion coefficient " $\mathrm{D}_{\mathrm{IP}}$ " is calculated by Eq. 8. "L" represents the specimen thickness in $\mathrm{mm}$.

$D_{\text {lag }}=\frac{L^{2}}{6 \times t_{\text {lag }}}$

$a_{\mathrm{i}}=\frac{\mathrm{di}}{\mathrm{dt}}$

$D_{\text {IP }}=\frac{0.04124 \times L^{2}}{0.2442 \times i_{\max }} \times \mathrm{a}_{\mathrm{i}}$

\subsection{Hydrogen diffusion and determination at elevated temperatures by carrier gas hot extraction}

\subsubsection{Hydrogen charging}

For the CGHE experiments, cylindrical samples were used. The specimens were previously ground with $\mathrm{SiC} 500$ grit paper and then electrochemically charged in an electrolyte with the same chemical composition that was used for the permeation experiments (section 3.2). The samples were charged in galvanostatic mode (constant charging current density) at $10 \mathrm{~mA} / \mathrm{cm}^{2}$ for $48 \mathrm{~h}$. This procedure minimized the possible concentration gradient in the sample as charging for $24 \mathrm{~h}$ resulted in comparable hydrogen amounts. In contrast to the permeation samples (one side is exposed to the charging electrolyte), the cylindrical samples had been entirely immersed in the charging electrolyte, as shown in Fig. 4b. The sample acted as working electrode (WE). For the electrical connection, a Pt wire was attached in the circumferential notch and removed after charging. Pt1800 electrode (Schott Instruments) was the counter electrode (CE).

\subsubsection{Hydrogen determination}

Hydrogen was detected at elevated temperatures by interpreting the effused hydrogen. In this case, a sample is heated by an external heat source in a semi-open chamber, which is permanently purged with carrier gas. This gas mixture is transferred to a detector. In our case, we used a CGHEanalyzer JUWE H-mat 221/G4 PHOENIX from Bruker Elementals AXS. This analyzer uses nitrogen as carrier gas and determines hydrogen via thermal conductivity detector. Further details can be found in [12, 43, 44].

\subsubsection{Diffusion coefficients}

The hydrogen diffusion coefficients were determined from quasi-isothermal heating of the samples at 100, 200, 300, and $400{ }^{\circ} \mathrm{C}$ by the use of an accelerated heating procedure. The heating time to the desired extraction temperature should be ideally zero as the hydrogen diffusion at constant extraction temperature is of interest. For that reason, the heating method encompasses the defined preheating of the infrared radiation furnace of the CGHE analyzer. Only the furnace is preheated for a defined time before the sample is inserted. After specimen insertion, the furnace decreases its temperature until the extraction temperature is reached. This results in an accelerated sample heating to the desired isothermal extraction temperature. Otherwise, the sample is heated too slow, and big thermal gradients can occur. Thus, the hydrogen diffusion coefficient would be an average value for a big temperature range with decreasing reliability. Further details on this heating procedure can be found in $[12,45]$.

For the calculation of the diffusion coefficients, the time-dependent hydrogen desorption/effusion rate was monitored and interpreted. The general procedure is shown in Fig. 6. In this connection, the initial hydrogen concentration " $\mathrm{C}_{0}$ " corresponds to the integral value of the blue curve.

The hydrogen analyzer operates with a step size of 0.2 s. The effused hydrogen amount during this time corresponds to a specific integral value, which is continuously subtracted from the total integral value (i.e., the hydrogen concentration " $\mathrm{C}_{0}$ "). The continuously reduced integral value for each step represents the time-dependent concentration " $\mathrm{C}_{(\mathrm{t})}$ ". The plot of " $\mathrm{C}_{(\mathrm{t})} / \mathrm{C}_{0}$ " vs time represents the remaining hydrogen amount in the sample with " $\mathrm{C}_{0}$ " as initial value.

A typical procedure for calculation of hydrogen diffusion coefficient is the use of the $t_{0.5}$ time, which indicates the time after $50 \%$ of the hydrogen effused from the sample [46-48], i.e., $50 \%$ of the integral value of the blue curve. Using this $t_{0.5}$ time, hydrogen diffusion coefficient can be calculated using Eq. 9 [46]. In case of the used diameter of $3 \mathrm{~mm}$ (radius of 1.5 $\mathrm{mm}$ ), this equation can be simplified to Eq. 10:

$D=\frac{0.064 \times r^{2}}{t_{0.5}}$

$D=\frac{0.144\left(\mathrm{~mm}^{2}\right)}{t_{0.5}}$

where $D$ is the diffusion coefficient in $\mathrm{mm}^{2} / \mathrm{s}, r$ is the sample radius in $\mathrm{mm}$, and $t_{0.5}$ in second. Due to the limited amount of available weld metal, a set of two samples was investigated for each temperature level.

\subsubsection{Temperature-dependent hydrogen concentrations}

The corresponding total hydrogen concentration in the samples was calculated via the automated integration of the 
Fig. 6 Determination of $t_{0.5}$ time

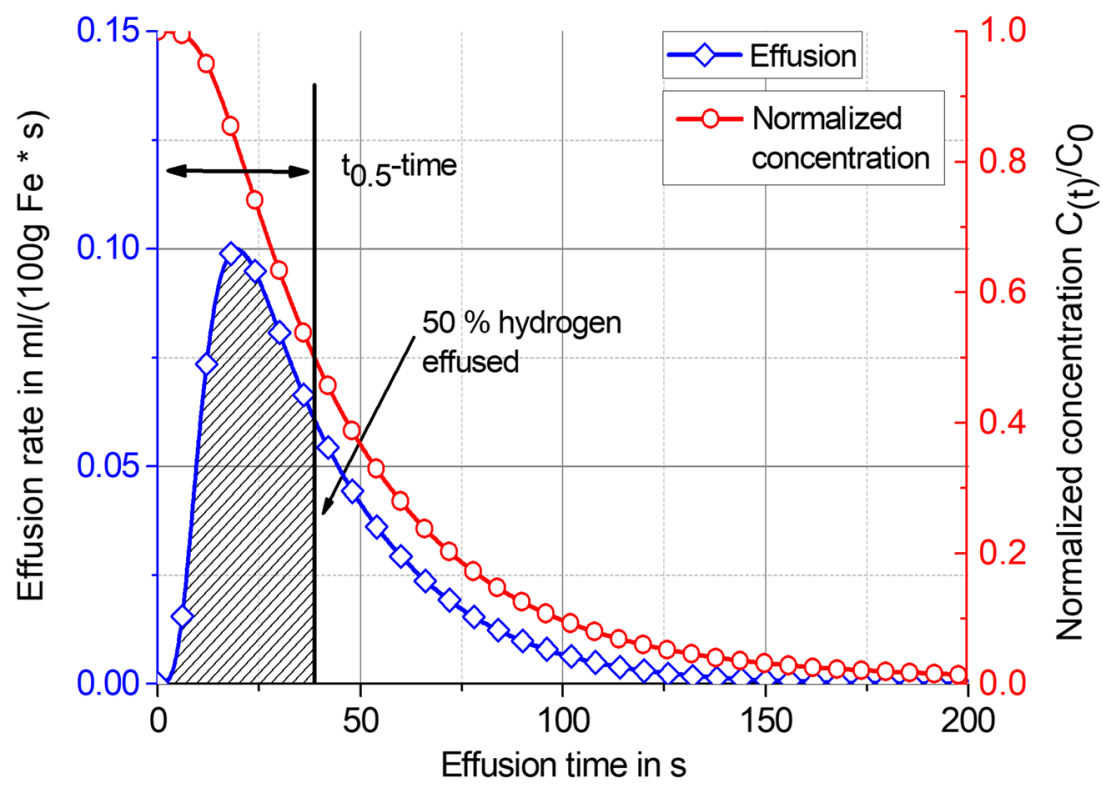

effusing hydrogen amount (rate) per time and the use of a predetermined calibration factor by the G4 Phoenix. This value is divided by the specimen weight for the calculation of the $\mathrm{HD}$ in $\mathrm{ml} / 100 \mathrm{~g} \mathrm{Fe}$ in accordance to ISO 3690 [49]. In our case, "HD $\mathrm{I}$ " represents the desorbing hydrogen amount (see blue line in Fig. 6) at the respective isothermal degassing temperature of $100,200,300$, or $400{ }^{\circ} \mathrm{C}$. The remaining concentration " $\mathrm{HD}_{\mathrm{II}}$ " is determined by heating the already degassed sample again to a temperature of $900{ }^{\circ} \mathrm{C}$. The sum of both is then "HD ${ }_{\text {tot }}$ ", the total hydrogen concentration.

\section{Results and discussion}

The results are divided into three parts. Section 4.1 shows the permeation experiments at room temperature, section 4.2 shows the hydrogen diffusion from 100 to $400{ }^{\circ} \mathrm{C}$, and section 4.3 presents the hydrogen solubility and trapping for the respective temperature range.

\subsection{Hydrogen diffusion at room temperature-influence of PWHT and diffusion direction}

Five experiments had been conducted for each heat treatment condition: three for perpendicular direction (labeled with I, II, III in Fig. 7) and two for longitudinal direction (labeled with IV, V in Fig. 7). The upper part of Fig. 7 shows the data for the perpendicular direction: part (a) shows the absolute current density in $\mathrm{mA} / \mathrm{cm}^{2}$ (a). Part (b) shows the respective normalized current density, whereas " $\mathrm{i}_{\max }$ " represents the maximum value (" 1 "). The lower part of Fig. 7 shows the permeation experiments for the longitudinal direction: part (c) shows the absolute current density in $\mathrm{mA} / \mathrm{cm}^{2}$ and part (d) the normalized data. In the parts (c) and (d), the experimental data of the experiments I-III is included for comparison (indicated by the gray colored curves).

The diffusion coefficients were calculated by the time-lag method ("D $\mathrm{D}_{\text {lag }}$ ", see Eq. 6) and the inflection point method ("D $\mathrm{D}_{\text {IP }}$ ", see Eq. 8). The obtained experimental data and the calculated data are shown in Table 2. Two different influences on hydrogen diffusion were investigated: (A) the heat treatment in terms of AW and PWHT and (B) the microstructure texture.

\section{A. Influence of heat treatment condition}

The heat treatment condition of the weld metal is very important as shown in Fig. $7 \mathrm{a}$ and c. It is obvious that the AW condition (three conducted experiments indicated by "As-welded IIII") delays the hydrogen diffusion. This is indicated by the prolonged lag-time " $\mathrm{t}_{\mathrm{lag}}$ " shown in Fig. $7 \mathrm{~b}$ and $\mathrm{d}$. In addition, the permeability " $\phi$ " (values given in Table 2 ) was generally decreased. A prolonged hydrogen diffusion and lower permeability at the same time, consequently call for higher number and/or higher efficiency of existing hydrogen traps in the AW condition.

In accordance to Table 2 and Fig.7, an accelerated hydrogen diffusion was obtained in PWHT condition (PWHT I-III). It is known that PWHT can cause two effects in the weld metal: (1) the annihilation of dislocations and the decrease of the respective density [23] or (2) the coarsening of precipitated carbides like $\mathrm{M}_{23} \mathrm{C}_{6}$ or $\mathrm{MX}$, which includes that the number of solute atoms in the matrix is decreased [22]. The effects can decrease the number of possible hydrogen traps and consequently increase the permeability and the calculated diffusion coefficients in case of PWHT. It is assumed that these factors had a comparable influence on our results although we did not conduct dislocation density measurement. Hence, the exact reason why the P91 WM in PWHT 
Fig. 7 Permeation experiments for perpendicular direction. Part (a) shows the absolute current density in $\mathrm{A} / \mathrm{mm}^{2}$ and (b) is the respective normalized data; comparison of permeation experiments for longitudinal direction. Part (c) shows the absolute current density in $\mathrm{A} / \mathrm{mm}^{2}$ and (d) is the respective normalized data
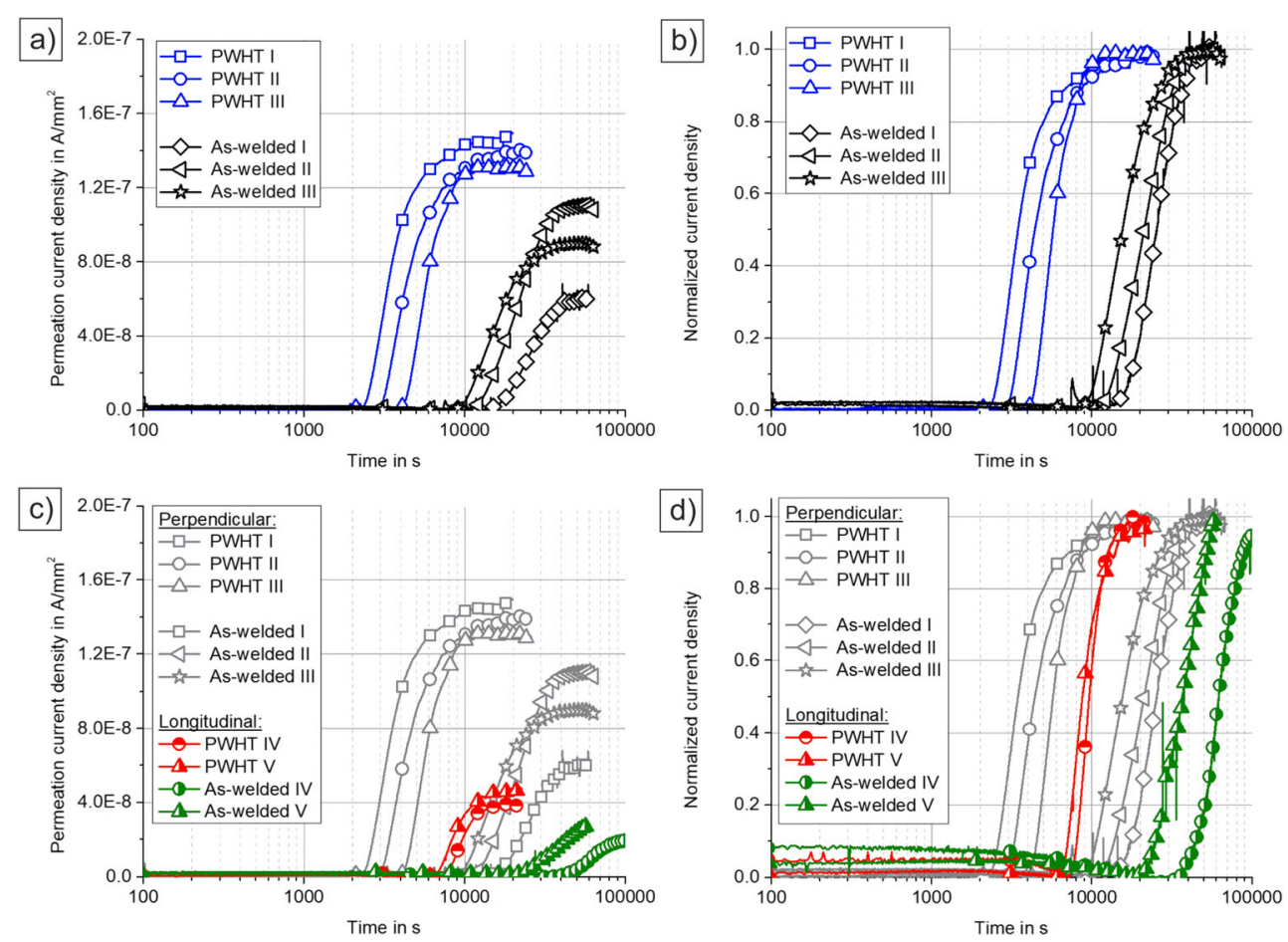

condition remains open. Nonetheless, it is assumed that the combination of a changed number of dislocations and precipitates is responsible, in accordance to $[30,31]$. But they accompanied by additional factors like grain boundaries, grain boundary area or volume fraction, and the kind of constituent microstructure phases (like austenite). All these crystal defects are necessary and influence the material creep strength, but they also represent hydrogen traps.

It seems to be unnecessary to define a "predominant" trap site for welding practice. It is a matter of fact, that PWHT is very helpful for both the mechanical properties and significantly reduced risk for HAC. But from the academic viewpoint, it is useful to have a closer look on the possible hydrogen traps. Exact diffusion coefficients and binding energies (see section 4.2) are for example very important for precise numerical simulations to model hydrogen effects on mechanical properties or the effectiveness of HRHT procedures [19, 20, 23].

The diffusion coefficients are in good agreement with the values given in $[30,31]$. If both the inflection point and the time-lag diffusion coefficients are compared, they showed ratios from 0.31 to 0.80 . From the analytical viewpoint, the time-lag method always results in lower diffusion coefficients compared with the inflection point method. The reason is the different interpretation of the experimental data.

The lag-time " $\mathrm{t}_{\text {lag }}$ " considers the influence of the necessary time for hydrogen adsorption at the sample surface, which are ignored in case of the inflection point method $[12,42,50]$. In other words, the time-lag method underestimates the hydrogen diffusion velocity in the material and leads to unrealistically low diffusion coefficients.
B. Influence of microstructure texture on possible preferred hydrogen diffusion

Additional experiments (As-welded IV-V and PWHT IV-V) were carried out to investigate the diffusivity vs microstructure texture. The data can be found in Table 2. The gray colored curves in Fig. $7 \mathrm{c}$ and $\mathrm{d}$ (longitudinal diffusion) are the experimental data from Fig. $7 \mathrm{a}$ and $\mathrm{b}$ (perpendicular). They are given for direct comparison of the different directions.

In this context, longitudinal diffusion means in case of a real weld joint the diffusion of hydrogen across the weld seam thickness (i.e., root to top layer), and perpendicular is the diffusion from the weld seam into the HAZ (assuming a butt joint).

Table 3 summarizes the obtained influence of the diffusion direction. For that purpose, the inflection diffusion coefficient is shown and the permeability for both AW and PWHT heat treatment condition.

Table 3 shows that the diffusion coefficients at AWcondition only showed small differences between the longitudinal and perpendicular direction within the same heat treatment condition. In contrast, the permeability (" $\Phi "$, see Table 2) as an expression for the diffusing hydrogen flux along the sample thickness was directly related to the diffusion direction. The permeability was always decreased in longitudinal direction for both AW and PWHT heat treatment condition. From the analytical viewpoint, diffusion coefficients without the consideration of the hydrogen flux at the same time are not suitable to identify a preferred diffusion direction. 
Table 2 Permeation data and calculated diffusion coefficients by time-lag and inflection point method

\begin{tabular}{|c|c|c|c|c|c|c|c|c|}
\hline \multicolumn{2}{|c|}{$\begin{array}{l}\text { Diffusion direction and } \\
\text { heat treatment condition }\end{array}$} & \multirow{2}{*}{$\begin{array}{l}\begin{array}{l}\text { Max. current } \\
\text { density }\end{array} \\
\mathrm{i}_{\max } \text { in } 10^{-8} \\
\mathrm{~A} / \mathrm{mm}^{2}\end{array}$} & \multirow{2}{*}{$\begin{array}{l}\text { Permeability } \\
\Phi \text { in } 10^{-13} \\
\mathrm{~mol} / \mathrm{mm}^{*} \mathrm{~s}\end{array}$} & \multirow{2}{*}{$\begin{array}{l}\text { Lag- } \\
\text { time } \\
\mathrm{t}_{0.63} \text { in } \\
\mathrm{s}\end{array}$} & \multirow{2}{*}{$\begin{array}{l}\text { Slope } \\
\text { a in } \\
10^{-12} \\
\text { A / } \\
\mathrm{mm}^{2} * \mathrm{~s}\end{array}$} & \multicolumn{2}{|c|}{$\begin{array}{l}\text { Diffusion } \\
\text { coefficients }\end{array}$} & \multirow{2}{*}{$\begin{array}{l}\text { Ratio } \\
\mathrm{D}_{\text {lag }} / \\
\mathrm{D}_{\mathrm{IP}}\end{array}$} \\
\hline & & & & & & $\begin{array}{l}\mathrm{D}_{\text {lag }} \text { in } \\
10^{-6} \\
\mathrm{~mm}^{2} / \mathrm{s}\end{array}$ & $\begin{array}{l}\mathrm{D}_{\mathrm{IP}} \text { in } \\
10^{-6} \\
\mathrm{~mm}^{2} / \mathrm{s}\end{array}$ & \\
\hline \multirow[t]{10}{*}{ Perpendicular } & AW I & 6.01 & 3.12 & 22,900 & 3.73 & 1.82 & 2.62 & 0.69 \\
\hline & AW II & 11.03 & 5.72 & 23,900 & 5.98 & 1.74 & 2.29 & 0.75 \\
\hline & AW III & 9.01 & 4.67 & 17,600 & 8.01 & 2.37 & 3.75 & 0.63 \\
\hline & Mean & 8.68 & 4.50 & 21,467 & 5.91 & 1.98 & 2.89 & - \\
\hline & \pm sigma & \pm 2.53 & \pm 1.31 & $\begin{array}{r} \pm \\
3,3- \\
86\end{array}$ & \pm 2.14 & \pm 0.34 & \pm 0.77 & - \\
\hline & $\begin{array}{l}\text { PWHT } \\
\text { I }\end{array}$ & 19.95 & 2.00 & 3,850 & 63.69 & 10.80 & 13.50 & 0.80 \\
\hline & $\begin{array}{c}\text { PWHT } \\
\text { II }\end{array}$ & 14.16 & 1.42 & 4,990 & 42.32 & 8.35 & 12.60 & 0.66 \\
\hline & $\begin{array}{c}\text { PWHT } \\
\text { III }\end{array}$ & 13.13 & 1.31 & 6,200 & 44.97 & 6.72 & 14.50 & 0.46 \\
\hline & Mean & 15.70 & 8.16 & 5,013 & 50.30 & 8.63 & 13.50 & - \\
\hline & \pm sigma & \pm 3.68 & \pm 1.91 & $\begin{array}{r} \pm \\
1,1- \\
75\end{array}$ & $\begin{array}{r} \pm \\
11 .- \\
60\end{array}$ & \pm 2.07 & \pm 0.90 & - \\
\hline \multirow[t]{8}{*}{ Longitudinal } & AW IV & 2.05 & 1.06 & 67,200 & 0.56 & 0.62 & 1.16 & 0.53 \\
\hline & AW V & 2.76 & 1.43 & 44,000 & 0.98 & 0.95 & 1.50 & 0.63 \\
\hline & Mean & 2.41 & 1.25 & 55,600 & 0.77 & 0.79 & 1.33 & - \\
\hline & \pm delta & \pm 0.35 & \pm 0.18 & $\begin{array}{r} \pm \\
11,- \\
600\end{array}$ & \pm 0.21 & \pm 0.17 & \pm 0.17 & - \\
\hline & $\begin{array}{l}\text { PWHT } \\
\text { IV }\end{array}$ & 3.39 & 1.76 & 10,200 & 10.56 & 4.13 & 13.20 & 0.31 \\
\hline & $\begin{array}{c}\text { PWHT } \\
\text { V }\end{array}$ & 4.80 & 2.49 & 9,500 & 11.14 & 4.43 & 9.76 & 0.45 \\
\hline & Mean & 4.10 & 2.13 & 9,850 & 10.85 & 4.28 & 11.48 & - \\
\hline & \pm delta & \pm 0.71 & \pm 0.37 & \pm 350 & \pm 0.29 & \pm 0.15 & \pm 1.72 & - \\
\hline
\end{tabular}

A reason for the pronounced effect of the diffusion direction on the permeability could be the different number interfacial bead areas. In longitudinal direction, hydrogen diffuses within the single weld beads of a weld layer and must penetrate several interfacial bead areas. In opposite, the perpendicular direction is characterized by diffusion along the layers (see Fig. 2b). "Conventional" hydrogen traps like dislocations, precipitates, grain boundaries, and microstructure constituents [28, 30, 31] could only explain the beneficial PWHT effect on diffusion. It is assumed that the obtained diffusion direction preference is comparable with materials with significant textures like austenitic-ferritic steels [51] or the effect of cold working on decreased hydrogen diffusivity [52].

Numerical calculations supported a so-called self-gathering effect of hydrogen enrichment in weld metal by solid-state phase transformation, which can appear several times in multi-layer welding [53]. It is assumed that the weld bead and layer sequence influence the hydrogen flux in a comparable way in terms of interfacial areas between the weld beads. It could not be identified what the exact reason was for the higher hydrogen flux in
Table 3 Diffusion direction influence on diffusion coefficient (" $D_{\text {IP") }}$ ) and permeability (“ $\Phi$ ") for both heat treatment conditions

\begin{tabular}{cccccc}
\hline \multirow{2}{*}{ Diffusion direction } & \multicolumn{2}{l}{ Perpendicular } & & \multicolumn{2}{l}{ Longitudinal } \\
\cline { 2 - 3 } \cline { 5 - 6 } Value & $\mathrm{D}_{\mathrm{IP}}$ & $\Phi$ & & $\mathrm{D}_{\mathrm{IP}}$ & $\Phi$ \\
\hline \multirow{2}{*}{ Unit } & $10^{-6} \mathrm{~mm}^{2} / \mathrm{s}$ & $10^{-13} \mathrm{~mol} / \mathrm{mm} \times \mathrm{s}$ & & $10^{-6} \mathrm{~mm}^{2} / \mathrm{s}$ & $10^{-13} \mathrm{~mol} / \mathrm{mm} \times \mathrm{s}$ \\
AW & 2.89 & 8.68 & & 1.33 & 2.41 \\
PWHT & 13.50 & 15.70 & & 11.48 & 4.10 \\
\hline
\end{tabular}


Fig. 8 Hydrogen diffusion from 100 to $400{ }^{\circ} \mathrm{C}$. Time-dependent effusion rate and corresponding remaining normalized hydrogen concentration for selected samples of AW condition (a), (b) and PWHT-condition (c), (d)
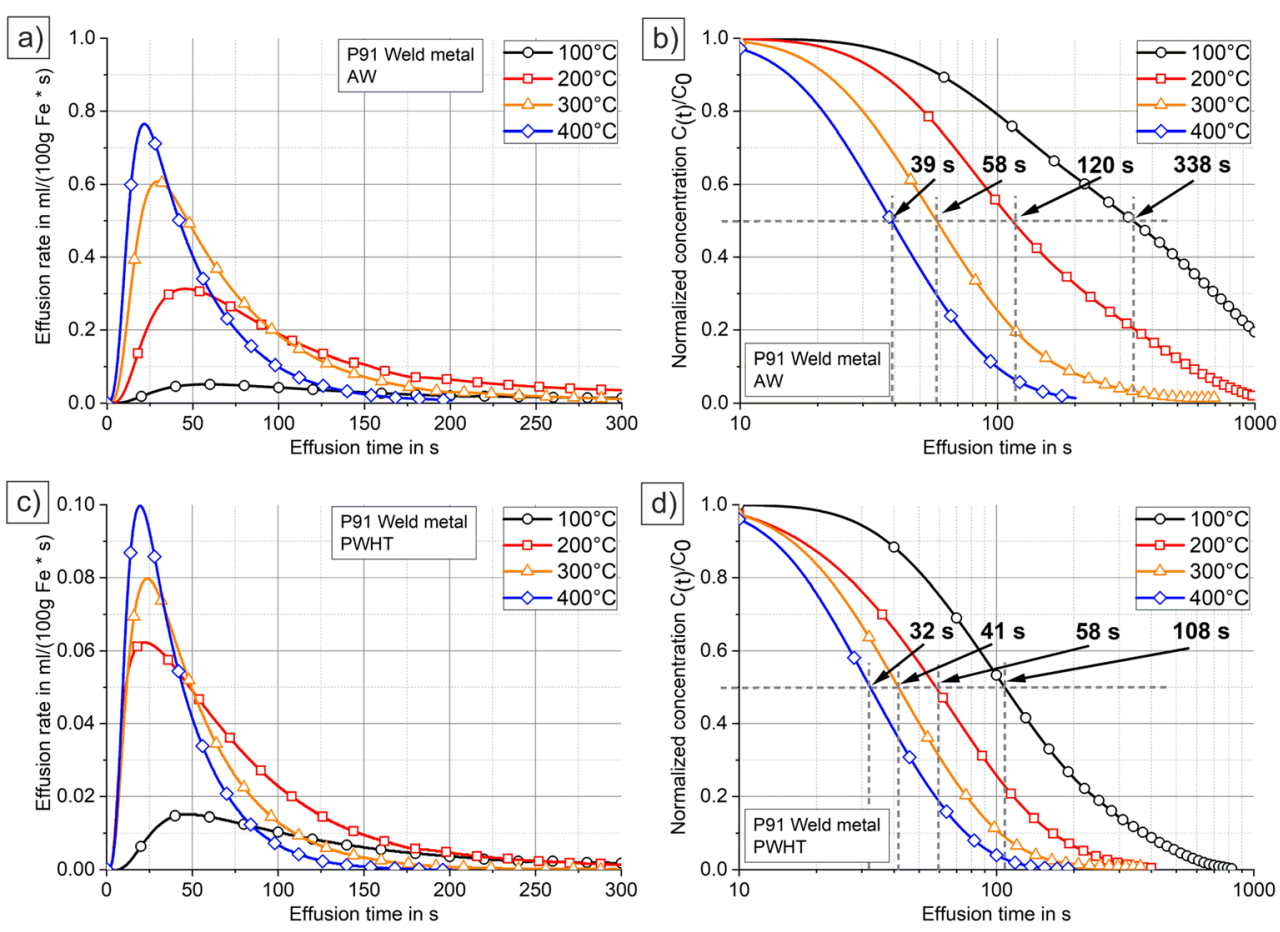

perpendicular direction. This effect could be also random and demands for an increased number of experiments with different materials with pronounced microstructure texture.

As shown in Table 3, the AW diffusion coefficients (only

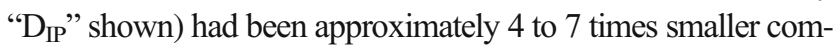
pared with the PWHT condition. Hence, a possible risk for delayed HAC consequently increases in as-welded and hard microstructure (like martensite in weld metal or HAZ) by significantly delayed diffusion [18-20].

For welding practice, the impact of PWHT on the calculated diffusion coefficients is predominant compared with the AW condition. But, it should be considered that thick-walled multilayer welded joints perhaps shows the obtained effect of delayed hydrogen diffusion across the root layer to the top layer. As mentioned, numerical calculations supported this effect of "aligned" hydrogen enrichment in weld metal [53].

\subsection{Hydrogen diffusion between 100 and $400{ }^{\circ} \mathrm{C}$}

Figure 8 shows the characteristic of temperature-dependent effusion rates and the corresponding normalized hydrogen concentrations remaining in the sample for both WM conditions. Parts (a) and (b) show the AW condition and (c) and (d) show the PWHT condition. The corresponding diffusion coefficients are shown in Table 4.

With increasing temperature, the hydrogen effusion curves show higher peak values (indicated by the effusion rate in $\mathrm{ml} /(\mathrm{s}$ $\times 100 \mathrm{~g} \mathrm{Fe}$ )) and shorter total diffusion times, which results in shorter $\mathrm{t}_{0.5}$ time. In accordance to $[45,46,48]$, the diffusion coefficients increase. Nonetheless, the P91 AW condition showed the lowest diffusion coefficients. This was valid with in the entire temperature that ranges from 100 to $400{ }^{\circ} \mathrm{C}$. Hence, the AW microstructure must have significantly increased the number of traps that delay the hydrogen diffusion. Independently of the microstructure condition, all diffusion coefficients had been within $10^{-4}$ to $10^{-3} \mathrm{~mm}^{2} / \mathrm{s}$ range. In accordance to Fig. 1 , they are comparable with those values reported in the literature [26, 32]. It is reasonable that the diffusion coefficients could be used to calculate possible HRHT times using models, for example used in $[19,20]$. In addition, it is obvious that high-alloyed $9 \% \mathrm{Cr}$ steels generally have lower diffusion coefficients compared with conventional low-alloyed $2.25 \% \mathrm{Cr}$ steels.

For the calculation of activation energy for diffusion, the Arrhenius plots are shown in Fig. 9. For that purpose the diffusion coefficients " $\mathrm{D}$ " are plotted on logarithmic scale vs. the absolute inverse temperature " $\mathrm{T}$ " (in K).

Table 4 Average values of $\mathrm{t}_{0.5}$ time (in second) and hydrogen diffusion coefficients $D$ (in $10^{-3} \mathrm{~mm}^{2} / \mathrm{s}$ ) with respective deviation (min./max. values)

\begin{tabular}{lccc}
\hline & T in ${ }^{\circ} \mathrm{C}$ & P91 AW & P91 PWHT \\
\hline $\mathrm{t}_{0.5}$ in second & 100 & $400 \pm 62$ & $163 \pm 55$ \\
& 200 & $127 \pm 14$ & $72 \pm 12$ \\
& 300 & $63 \pm 5$ & $42 \pm 1$ \\
$\mathrm{D}$ in $10^{-3} \mathrm{~mm}^{2} / \mathrm{s}$ & 400 & $38 \pm 1$ & $33 \pm 1$ \\
& 100 & $0.4 \pm 0.1$ & $1.0 \pm 0.3$ \\
& 200 & $1.2 \pm 0.0$ & $2.1 \pm 0.3$ \\
& 300 & $2.3 \pm 0.2$ & $3.4 \pm 0.0$ \\
& 400 & $3.9 \pm 0.1$ & $4.3 \pm 0.1$ \\
\hline
\end{tabular}




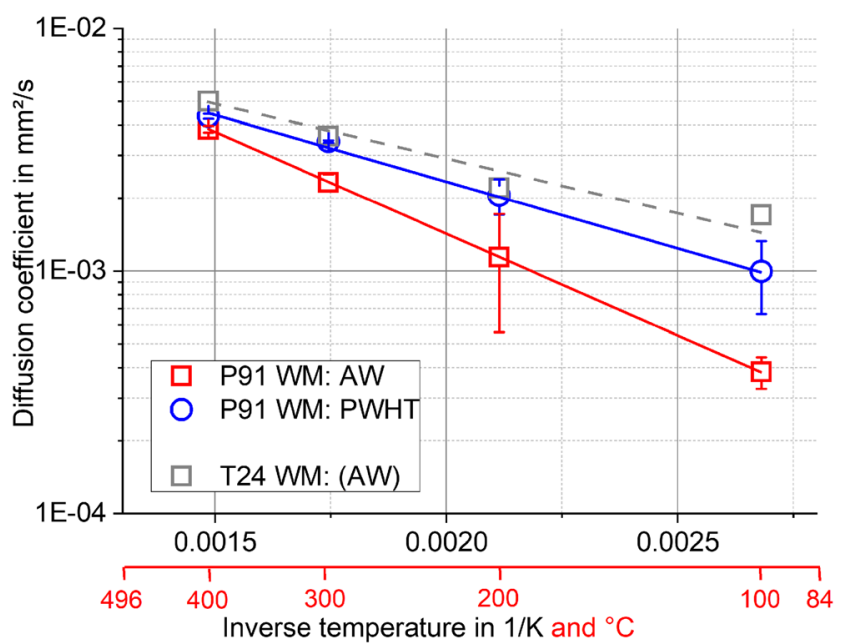

Fig. 9 Hydrogen diffusion coefficients from 100 to $400{ }^{\circ} \mathrm{C}$ (T24 WM given for comparison, taken from [12])

The P91 WM in AW condition had the steepest slope of the Arrhenius plots. This indicates a higher trapping energy. The slope can be calculated by the analogy of the Arrhenius equation to a simple linear function (Eq. 11).

$y=n+m \times x$

$E_{\mathrm{A}}=m \times R$

In accordance to Eq. 12, which is the activation energy, " $E_{\mathrm{A}}$ is then calculated by determining " $m$ " from the Arrhenius-fit and multiplying with " $R$ " (universal gas constant). Table 5 shows the calculated data for the diffusion constant " $\mathrm{D}_{0}$ ", the Arrhenius slope " $\mathrm{m}$ ", the activation energy " $\mathrm{E}_{\mathrm{A}}$ " and the corresponding regression coefficient.

Both Arrhenius plots showed very good regression model quality. The AW condition had 1.5 times higher calculated activation energy for hydrogen release from the traps $(16.2 \mathrm{~kJ} / \mathrm{mol}$ for AW compared with $10.4 \mathrm{~kJ} / \mathrm{mol}$ for PWHT). Nonetheless, both values indicate so-called reversible trapping (as $E_{\mathrm{A}}$ is below $30 \mathrm{~kJ} / \mathrm{mol}$ [54]). This means hydrogen is bound by traps but not permanently. Corresponding major trap sites in the WM can be dislocations, grain boundaries, and the manifold precipitates in P91 WM [22-24, 26]. The PWHT must have the most important influence. Possible effects are the reduction of the number of dislocations [23] by PWHT, annealing [55], or the growth of carbides [22], both effects reduce the number of possible hydrogen traps in the weld metal. This behavior is consistent with the experiments shown in section 3.1 and 3.2.

For that reason, a PWHT is beneficial for hydrogen diffusion in terms of decreased number of hydrogen traps. This has significant influence on a necessary PWHT of the weld joint. If welding must be interrupted, it has to be ensured that the weld is maintained at the interpass or preheat temperature. Otherwise hydrogen diffusion significantly decreases with decreasing temperature. Considering the still present martensitic microstructure (before PWHT), a few ppm or ml/100 g Fe are already high enough for full embrittlement of the microstructure [13, 14]. In case of the $\mathrm{P} 91$ weld metal in $\mathrm{AW}$ condition, the risk for delayed HAC consequently increases if no HRHT is carried out before the weld is cooled down for the final martensitic transformation.

It is worth mentioning that former investigations showed a different behavior for TIG-welded T24/7CrMoVTiB10-10 [12]. In this case, the "AW" condition had comparable $E_{\mathrm{A}}$ values like the P91 WM PWHT condition $(7.4 \mathrm{~kJ} / \mathrm{mol}$ compared with $10.4 \mathrm{~kJ} / \mathrm{mol}$ ). It is reasonable that this value was influenced by the different welding process (TIG). The TIG welding typically encompasses thinner beads and layers, which results in a different tempering influence during multi-layer welding. Hence, a "partially" annealed microstructure can be assumed already in the as-welded condition. But it must be considered that the chemical composition of T24 is different from that of the P91. The reason is the reduced amount of alloy elements due to T24 low alloy concept of $2.25 \mathrm{Cr}-1 \mathrm{Mo}-0.25 \mathrm{~V}$ with additions of $\mathrm{B}$ and $\mathrm{Ti}$ [12]. This results in a reduced number of precipitates (i.e., available hydrogen traps). In addition, in [30] it was reported that the number of solute atoms (like $\mathrm{Cr}$ or $\mathrm{Mo}$ ) plays a dominant role in hydrogen trapping. Their number varies with the heat treatment temperature, which is a reasonable explanation for the difference of TIG weld metal in AW condition (higher annealing temperature due to the small weld beads and higher heat input compared with GMAW). Combined with the microstructure (T24 mostly bainitic, P91 mostly martensitic), this can be an explanation for the similar diffusion coefficients of P91 PWHT-WM and T24 "self-annealed" AW-WM as bainite and martensite typically do not show different diffusion behavior $[12,56]$ even in a coarse or fine-grained HAZ microstructure [12]. From that point of view, it is difficult to identify, what has the major influence on the diffusion: the chemical composition, the welding procedure, the microstructure, or a combination of all. It is suggested to perform further thermal desorption analysis (TDA) as the calculation of " $\mathrm{E}_{\mathrm{A}}$ " (as value for a possible major hydrogen trap site) only by diffusion coefficients can be misleading [43, 57].

The combined experimental data from section 4.1 and section 4.2 suggest that the AW condition always had the lowest hydrogen diffusion coefficients for the range from room

Table 5 Calculated activation energies " $\mathrm{E}_{\mathrm{A}}$ " within the temperature interval from 100 to $400{ }^{\circ} \mathrm{C}$ (min./max values)

\begin{tabular}{ccccc}
\hline Condition & $\mathrm{D}_{0}$ in $10^{-3} \mathrm{~mm}^{2} / \mathrm{s}$ & Slope $\mathrm{m}$ & $\begin{array}{c}\mathrm{E}_{\mathrm{A}} \text { in } \\
\mathrm{k} \mathrm{J} / \\
\mathrm{mol}\end{array}$ & $R^{2}$ \\
\hline AW & 70.6 & 1959 & 16.2 & 0.99 \\
PWHT & 29.1 & 1255 & 10.4 & 0.99 \\
\hline
\end{tabular}


temperature to approximately $300{ }^{\circ} \mathrm{C}$. This temperature is close to the typical interpass temperature (in our case 280 ${ }^{\circ} \mathrm{C}$ ), as well as the HRHT temperature of 300 to $350{ }^{\circ} \mathrm{C}$. It is obvious that a HRHT at elevated temperatures should be beneficial in terms of HAC avoidance by reducing the hydrogen concentration in the microstructure. Nonetheless, the diffusion coefficients are an effective value to assess the hydrogen atoms velocity within a given microstructure. But they do not include any information on possible trapping of residual hydrogen. For example, it is an economic question if HRHT temperature could be reduced to $200{ }^{\circ} \mathrm{C}$ to remove the hydrogen from the weld metal. The problem is that HRHT procedure needs more energy, the higher the intended temperature is, i.e., a question of the energy costs. For that purpose, the CGHE specimens were degassed for a second time at $900{ }^{\circ} \mathrm{C}$ to identify possible trapped hydrogen amounts. The results are shown in section 4.3.

\subsection{Hydrogen solubility and trapping from 100 to 400 ${ }^{\circ} \mathrm{C}$}

The isothermal degassing experiments allowed the calculation of trapped hydrogen concentrations. Table 6 shows the measured hydrogen concentrations. "HD," represents the desorbing hydrogen amount (corresponding integral value of AW curves in Fig. 8a and PWHT-curves in Fig. $8 \mathrm{c})$ at the respective isothermal temperature of 100 to 400 ${ }^{\circ} \mathrm{C}$. Subsequently, the remaining concentration " $\mathrm{HD}_{\mathrm{II}}$ " is determined by heating the degassed sample for a second time to $900{ }^{\circ} \mathrm{C}$. The sum of both is then " $\mathrm{HD}_{\text {tot }}$ ", the total hydrogen concentration.

It is obvious that the decreased diffusion coefficients correlate (see Table 3 ) to the measured hydrogen concentration. In the "as-welded" condition, the P91 WM had a total hydrogen concentration between 43 and $54 \mathrm{ml} / 100 \mathrm{~g}$ Fe. This value decreased to 3 and $5 \mathrm{ml} / 100 \mathrm{~g} \mathrm{Fe}$ in case of the PWHT condition. Both heat treatment conditions showed significant amount of trapped hydrogen at 100 ${ }^{\circ} \mathrm{C}$. In this case, the AW condition nearly $50 \%$ of the total hydrogen had been trapped (approximately $20 \mathrm{ml} / 100 \mathrm{~g}$ Fe). At $200{ }^{\circ} \mathrm{C}$ any trapped hydrogen was measured. That means for HRHT a minimum temperature of $200{ }^{\circ} \mathrm{C}$ is recommended as any hydrogen would remain in the (martensitic) weld metal. This recommendation does not include any HRHT time. This time is explicitly dependent on the weld joint thickness as well as on the applied diffusion coefficients $[15,20]$. The measured hydrogen concentrations cannot represent real weld samples as typically those concentrations of 10 to $20 \mathrm{ml} / 100 \mathrm{~g}$ Fe are not reached during welding. Nonetheless, already small amounts of hydrogen can have a pronounced effect on the mechanical properties of P91 WM.

\section{Summary and conclusions}

In this study, the hydrogen diffusion in 9\% Cr steel P91 multi-layer weld metal was studied in AW and PWHT condition. Diffusion was investigated at room temperature (permeation experiments) and for two different microstructure directions. Hydrogen diffusion was investigated at elevated temperatures and trapped hydrogen concentrations were measured (by CGHE) within a HAC-related temperature that ranges from 100 to $400{ }^{\circ} \mathrm{C}$. The following conclusions can be drawn from the present study:

- The permeation experiments at room temperature showed that the perpendicular direction was identified as preferred diffusion direction for both heat treatment conditions and is expressed by the permeability (" $\Phi ”)$. The permeability, i.e., the hydrogen flux was significantly higher in perpendicular direction. In opposite, no preferred diffusion direction can be identified if the calculated diffusion coefficients are regarded. The problem is that the diffusion coefficients only describe the "speed" of the diffusion
Table 6 Measured temperaturedependent hydrogen concentration $\mathrm{HD}_{\mathrm{I}}$, remaining $\mathrm{HD}_{\mathrm{II}}$, and summarized $\mathrm{HD}_{\text {tot }}$

\begin{tabular}{|c|c|c|c|c|c|}
\hline & \multirow[t]{2}{*}{ Temp. in ${ }^{\circ} \mathrm{C}$} & \multicolumn{3}{|c|}{ Hydrogen concentration in $\mathrm{ml} / 100 \mathrm{~g} \mathrm{Fe}$} & \multirow[t]{2}{*}{$\mathrm{HD}_{\mathrm{II}} / \mathrm{HD}_{\text {tot }}(\%)$} \\
\hline & & $\mathrm{HD}_{\mathrm{I}}$ & $\mathrm{HD}_{\text {II }}$ & $\mathrm{HD}_{\text {tot }}$ & \\
\hline \multirow[t]{4}{*}{ AW } & 100 & $23.1 \pm 7.5$ & $20.8 \pm 7.8$ & 43.9 & 52 \\
\hline & 200 & $49.1 \pm 1.3$ & 0.0 & 49.1 & 0 \\
\hline & 300 & $54.0 \pm 7.7$ & 0.0 & 54.0 & 0 \\
\hline & 400 & $45.6 \pm 7.8$ & 0.0 & 45.6 & 0 \\
\hline \multirow[t]{4}{*}{ PWHT } & 100 & $3.1 \pm 1.1$ & $0.3 \pm 0.1$ & 3.4 & 10 \\
\hline & 200 & $5.1 \pm 1.0$ & 0.0 & 5.1 & 0 \\
\hline & 300 & $4.8 \pm 0.1$ & 0.0 & 4.8 & 0 \\
\hline & 400 & $4.5 \pm 0.3$ & 0.0 & 4.5 & 0 \\
\hline
\end{tabular}


process but do not say anything about the amount of the diffusing species. This is more important in terms of a crack-critical hydrogen concentration. Hence, the diffusion coefficients can be used for simple calculations but cannot express the microstructure texture dependence in this study. For that purpose, the permeability is more suitable.

- CGHE experiments showed that AW condition had significant effect on diffusion also at elevated temperatures. This effect was to delay the necessary time for hydrogen desorption from weld metal samples. This means that the number of active hydrogen traps is increased compared with the PWHT condition. Consequently, the hydrogen diffusion coefficients of the AW condition had been smaller compared with the PWHT condition. This difference was determined up to $300{ }^{\circ} \mathrm{C}$. The calculated activation energies showed reversible hydrogen trapping (expressed by the activation energy) for both heat treatment conditions. Due to the complicated discussion on predominant hydrogen traps, it can only be assumed that in dislocations and precipitates are perhaps the predominant hydrogen traps in AW condition. Nonetheless, the hydrogen diffusion is influenced by additional factors like grain boundaries, martensite lath as well as residual microstructure constituents.

- For welding applications delayed hydrogen diffusion must be anticipated. If welding must be interrupted or no DHT/HRHT is performed, the risk for delayed HAC of the weld joint consequently increases as diffusion coefficients decrease. From our study, a minimum HRHT temperature of $200{ }^{\circ} \mathrm{C}$ is recommended. The reason is that below this temperature significant amounts of hydrogen can still be trapped.

- The absorbed hydrogen concentration consequently increased for the AW condition. This is a consequence of the decreased hydrogen diffusion coefficients within the entire temperature range. The PWHT condition showed approximately total hydrogen concentration of 3 to $5 \mathrm{ml} / 100 \mathrm{~g} \mathrm{Fe}$. The AW condition showed a total absorbed hydrogen concentration of 43 to $54 \mathrm{ml} / 100 \mathrm{~g}$ $\mathrm{Fe}$, whereas approximately $21 \mathrm{ml} / 100 \mathrm{~g} \mathrm{Fe}$ was still trapped at $100{ }^{\circ} \mathrm{C}$.

\section{References}

1. Hahn B, Bendick W (2008) Rohrstähle für moderne Hochleistungskraftwerke. 3R International 47:3-12

2. Coleman KK, Newell WF Jr (2007) P91 and beyond - Welding the new-generation Cr-Mo alloys for high-temperature service. Weld J 86(8):29-33
3. Dhooge A, Vekeman J (2005) New generation 21/4Cr steels T/P 23 and T/P 24 weldability and high temperature properties. Weld World 49:75-93. https://doi.org/10.1007/bf03266492

4. Agüero A, Audigié P, Rodriguez C et al (2017) Protective coatings for high temperature molten salt heat storage systems in solar concentration power plants. SolarPACES2017 Conf AIP Conf Proc 2033(1):90001-1-090001-8. https://doi.org/10.1063/1.5067095

5. Mukherjee S, Jamnapara NI (2015) Materials research and development opportunities in fusion reactors. Proc Indian Natn Sci Acad 81(4):827-839. https://doi.org/10.16943/ptinsa/2015/v81i4/48299

6. Husemann RU, Devrient S, Kilian R (2012) Cracking mechanism in high temperature water-T24 Root cause analysis program. In: 38th VDI-Jahrestagung Schadensanalyse in Kraftwerken. VDIWissensforum, Düsseldorf, pp 87-103

7. Hoffmeister H, Boellinghaus $\mathrm{T}$ (2014) Modeling of combined anodic dissolution/hydrogen-assisted stress corrosion cracking of low-alloyed power plant steels in high-temperature water environments. Corros Sci 70:563-578. https://doi.org/10.5006/1048

8. Garet M, Brass AM, Haut C, Guttierez-Solana F (1998) Hydrogen trapping on non-metallic inclusions in Cr-Mo low alloyed steels. Corros Sci 40:1073-1086. https://doi.org/10.1016/S0010-938x(98) 00008-0

9. Albert SK, Ramasubbu V, Parvathavarthini N, Gill TPS (2003) Influence of alloying on hydrogen-assisted cracking and diffusible hydrogen content in Cr-Mo steel welds. Sadhana 28:383-393. https://doi.org/10.1007/bf02706439

10. Steppan E, Mantzke P, Steffens BR, Rhode M, Kannengiesser T (2017) Thermal desorption analysis for hydrogen trapping in microalloyed high-strength steels. Weld World 61:637-648. https://doi.org/10.1007/s40194-017-0451-z

11. ISO 17462-1:2004 Destructive tests on welds in metallic materials cold cracking tests for weldments - Arc welding processes, Part 1: General.

12. Rhode M (2016) Hydrogen diffusion and effect on degradation in welded microstructures of creep-resistant low-alloyed steels. BAMDissertationsreihe No. 148, Bundesanstalt für Materialforschung und -prüfung (BAM), Berlin, Germany.

13. Rhode M, Steger J, Steppan E, Kannengiesser T (2016) Effect of hydrogen on mechanical properties of a reactor pressure vessel steel grade. Weld World 60(4):623-638. https://doi.org/10.1007/s40194016-0325-9

14. Pillot S, Coudreuse L (2012) Hydrogen induced disbonding and embrittlement of steels used in petrochemical refining. In: Gangloff RP, Somerday BP (eds) Gaseous Hydrogen embrittlement of Materials in Energy Technologies, The problem, its characterization and effects on particular alloy classes, vol 1. Woodhead Publishing, Cambridge, pp 51-93. https://doi.org/10.1533/ 9780857093899.1.51

15. Bailey N, Coe FR, Gooch TG, Hart PHM, Jenkins N, Pargeter RJ (2004) Welding steels without hydrogen cracking, 2nd revised ed. Woodhead Publishing, Oxford.

16. Pitrun M, Nolan D, Dunne D (2004) Diffusible hydrogen content in rutile flux-cored arc welds as a function of the welding parameters. Weld World 48(1/2):2-13. https://doi.org/10.1007/BF03266408

17. Nevasmaa P, Laukkanen A (2005) Assessment of hydrogen cracking risk in multipass weld metal of $2.25 \mathrm{Cr}-1 \mathrm{Mo}-0.25 \mathrm{~V}-\mathrm{TiB}$ (T24) boiler steel. Weld World 49(7-8):45-58. https://doi.org/10.1007/ BF03263423

18. Abe M, Nakatani N, Namatame N, Terasaki T (2012) Influence of dehydrogenation heat treatment on hydrogen distribution in multilayer welds of Cr-Mo-V steel. Weld World 56:114-123. https://doi. org/10.1007/BF03321355

19. Mente T, Boellinghaus T, Schmitz-Niederau M (2012) Heat treatment effects on the reduction of hydrogen in multi-layer highstrength weld joints. Weld World 56(7/8):26-36. https://doi.org/ 10.1007/BF03321362 
20. Alexandrov BT (2003) Hydrogen diffusion coefficient and modeling of hydrogen behaviour in welded joints of structural steels. Weld World 47(9/10):21-29. https://doi.org/10.1007/BF03266397

21. Boellinghaus T, Hoffmeister H, Middel C (1996) Scatterbands for hydrogen diffusion coefficients in steel having a ferritic or martensitic microstructure and steels having an austenitic microstructure at room temperature. Weld World 37(1):16-23

22. Fallahmohammadi E et al (2014) Hydrogen diffusion into three metallurgical microstructures of a C-Mn X65 and low alloy F22 sour service steel pipelines. Int J Hydro Energ 39(25):1330013313. https://doi.org/10.1016/j.ijhydene.2014.06.122

23. Brass AM, Guillon F, Vivet S (2004) Quantification of hydrogen diffusion and trapping in $2.25 \mathrm{Cr}-1 \mathrm{Mo}$ and $3 \mathrm{Cr}-1 \mathrm{Mo}-\mathrm{V}$ steels with the electrochemical permeation technique and melt extraction. Metall Mater Trans A 35:1449-1464. https://doi.org/10.1007/ s11661-004-0253-y

24. Parvathavarthini N, Saroja S, Dayal RK, Khatak HS (2001) Studies on hydrogen permeability of $2.25 \mathrm{Cr} \%-1 \% \mathrm{Mo}$ ferritic steel: correlation with microstructure. J Nucl Mater 288:187-196. https://doi. org/10.1016/S0022-3115(00)00706-6

25. Cheng $\mathrm{X}$ et al (2018) Hydrogen diffusion and trapping in Vmicroalloyed mooring chain steels. Mater Lett 213:118-121. https://doi.org/10.1016/j.matlet.2017.11.029

26. Padhy GK et al (2015) Influence of temperature and alloying on the apparent diffusivity of hydrogen in high strength steel. Int J Hydro Energ 40(20):6714-6725. https://doi.org/10.1016/j.ijhydene.2015. 03.153

27. Valentini R, Solina A (1994) Influence of microstructure on hydrogen embrittlement behavior of 2.25Cr-1Mo steel. Mater Sci Tech 10(10):908-914. https://doi.org/10.1179/mst.1994.10.10.908

28. Pereira PAS, Gomes Franco CDS et al (2015) Hydrogen effects on the microstructure of a $2.25 \mathrm{Cr}-1 \mathrm{Mo}-0.25 \mathrm{~V}$ steel welded joint. Int $\mathrm{J}$ Hydro Energ 40(47):17136-17143. https://doi.org/10.1016/j. ijhydene.2015.07.095

29. Perng TP, Altstetter CJ (1986) On the effective hydrogen permeability in metastable beta-titanium alloy, niobium and $2.25 \mathrm{Cr}-1 \mathrm{Mo}$ ferritic steel. Metall Trans A 17(11):2086-2090. https://doi.org/10. 1007/BF02645009

30. Parvathavarthini N, Saroja S, Dayal RK (1999) Influence of microstructure on the hydrogen permeability of $9 \% \mathrm{Cr}-1 \% \mathrm{Mo}$ ferritic steel. J Nucl Mater 264:35-47. https://doi.org/10.1016/S00223115(98)00486-3

31. Hurtado-Noreña C, Bruzzoni P (2010) Effect of microstructure on hydrogen diffusion and trapping in a modified $9 \% \mathrm{Cr}-1 \% \mathrm{Mo}$ steel. Mater Sci Eng A 527(3):410-416. https://doi.org/10.1016/j.msea. 2009.08.025

32. Padhy GK, Ramasubbu V, Murugesan N et al (2013) Determination of apparent diffusivity of hydrogen in $9 \mathrm{Cr}-1 \mathrm{MoVNbN}$ steel using hot extraction-PEMHS technique. Int J Hydrog Energ 8:1068310693. https://doi.org/10.1016/j.ijhydene.2013.06.077

33. Bouhatte J, Legrand E, Feaugas X (2011) Computational analysis of geometrical factors affecting experimental data extracted from hydrogen permeation tests: I - Consequences of trapping. Int $\mathrm{J}$ Hydro Energ 36(19):12644-12652. https://doi.org/10.1016/j. ijhydene.2011.06.143

34. Legrand E et al (2014) Computational analysis of geometrical factors affecting experimental data extracted from hydrogen permeation tests: III - Comparison with experimental results from the literature. Int J Hydro Energ 39(2):1145-1155. https://doi.org/10. 1016/j.ijhydene.2013.10.099

35. Porter DA, Easterling KE, Sherif M (2009) Phase transformations in metals and alloys, 3rd revised ed. Routledge, Abingdon, United Kingdom

36. Crank J (1979) The mathematics of diffusion, 2nd edn. Clarendon Press, Oxford, United Kingdom.
37. EN ISO 17634:2015 Welding consumables - Tubular cored electrodes for gas shielded metal arc welding of creep-resisting steels Classification.

38. Manufacturer specification for BÖHLER C 9 MV Ti-FD.

39. Pandey C, Mahapatra MH, Kumar P, Saini N (2018) Some studies on P91 steel and their weldments. J Alloys Compd 743:332-364. https://doi.org/10.1016/j.jallcom.2018.01.120

40. Devanathan MAV, Stachurski Z (1963) A technique for the evaluation of hydrogen embrittlement characteristics of electroplating bath. J Electrochem Soc 110(8):886-890. https://doi.org/10.1149/ 1.2425894

41. ISO 17081:2014 Method of measurement of hydrogen permeation and determination of hydrogen uptake and transport in metals by an electrochemical technique.

42. Dresler W, Froberg MG (1972) Über ein vereinfachtes Verfahren zur Bestimmung des Diffusionskoeffizienten von Wasserstoff in festen Metallen. Zeitschrift für Materialkunde 63(4):204-209

43. Rhode M, Schaupp T, Muenster C, Mente T et al (2019) Hydrogen determination in welded specimens by carrier gas hot extraction- $\mathrm{a}$ review on the main parameters and their effects on hydrogen measurement. Weld World 63(2):511-526. https://doi.org/10.1007/ s40194-018-0664-9

44. Salmi S, Rhode M, Juettner S, Zinke M (2015) Hydrogen determination in 22MnB5 Steel grade by use of carrier gas hot extraction technique. Weld World 59:137-144. https://doi.org/10.1007/ s40194-014-0186-Z

45. Muenster C, Rhode M, Mente T, Boellinghaus Th (2016) Influence of Experimental Conditions and Calculation Method on Hydrogen Diffusion Coefficient Evaluation at Elevated Temperatures. In: Somerday BP, Sofronis P (eds.) International Hydrogen Conference (IHC 2016): Materials Performance in Hydrogen Environments, pp. 495-503. doi: https://doi.org/10.1115/1. 861387 ch56

46. Fromm E, Gebhardt E (1976) Gase und Kohlenstoff in Metallen. Springer, Berlin, Germany

47. Iacoviello F, Galland J, Habashi M (1998) A thermal outgassing method (T.O.M.) to measure the hydrogen diffusion coefficients in austenitic, austeno-ferritic and ferritic-pearlitic steels. Corros Sci 40(8):1281-1293. https://doi.org/10.1016/S0010-938X(97)001455

48. Egorov NI, Emelyanenko AA (2011) Investigation of the effective coefficient of hydrogen diffusion in the conditions of the thermal cycle of welding. Weld Inter 26:958-962. https://doi.org/10.1080/ 09507116.2012 .694637

49. EN ISO 3690:2018 Welding and allied processes - Determination of hydrogen content in arc weld metal.

50. Rhode M, Steger J, Kannengießer T (2014) Approach for calculation of apparent hydrogen diffusion coefficients with permeation experiments in $\mathrm{CrMoV}$ steel weld joints, Proceedings of the Steel \& Hydrogen 2014. Ghent, Belgium, pp 670-674

51. Owczarek E, Zakroczymski T (2000) Hydrogen transport in a duplex stainless steel. Acta Mater 48(12):3059-3070. https://doi.org/ 10.1016/S1359-6454(00)00122-1

52. Szklarska-Smialowska Z, Xia Z (1997) Hydrogen trapping by cold worked X-52 steel. Corros Sci 39:2171-2180. https://doi.org/10. 1016/S0010-938X(97)00100-5

53. Xiong Z, Zheng W, Tang L, Yang J (2019) Self-gathering effect of the hydrogen diffusion in welding induced by the solid-State phase transformation. Materials 12(18):2897. https://doi.org/10.3390/ ma12182897

54. Pressouryre GM (1979) A classification of hydrogen traps in steel. Metall Mater Trans A 10(10):1571-1573. https://doi.org/10.1007/ BF02661939

55. Pesicka KR, Dronhofer A, Eggeler G (2003) The evolution of dislocation density during heat treatment and creep of tempered 
martensite ferritic steels. Acta Mater 51(16):4847-4862. https://doi. org/10.1016/S1359-6454(03)00324-0

56. Perez-Escobar D, Verbeken K, Duprez L, Verhaege M (2012)

Evaluation of hydrogen trapping in high-strength steels by thermal desorption spectroscopy. Mater Sci Eng A 551:50-58. doi:

57. Rhode M, Mente T, Steppan E et al (2018) Hydrogen trapping in T24 Cr-Mo-V steel weld joints - microstructure effect vs. experimental influence on activation energy for diffusion. Weld World 62(2):277-287. https://doi.org/10.1016/S1359-6454(03) 00324-0

Publisher's note Springer Nature remains neutral with regard to jurisdictional claims in published maps and institutional affiliations. 